\title{
Short bowel syndrome and clopidogrel non-responsiveness: a new indication for platelet aggregometry?
}

\author{
Gina Hadley, ${ }_{1}$ Paul Harrison, ${ }^{2}$ David Adlam, ${ }^{3}$ Robin P Choudhury ${ }^{4}$
}

${ }^{1}$ University of Oxford, Oxford, UK

${ }^{2}$ School of Immunity and Infection, University of Birmingham, Birmingham, UK ${ }^{3}$ Department of Cardiovascular Sciences, University of Leicester, Leicester, UK ${ }^{4}$ Division of Cardiovascular Medicine Radcliffe, Department of Medicine, University of Oxford, Oxford, UK

Correspondence to Dr Gina Hadley, gina.hadley@ndm.ox.ac.uk

Accepted 11 February 2014

CrossMark

To cite: Hadley $G$, Harrison P, Adlam D, et al. BMJ Case Rep Published online: [please include Day Month Year] doi:10.1136/ bcr-2013-202241

\section{DESCRIPTION}

A 74-year-old woman presented with unstable angina. Coronary angiography demonstrated severe single-vessel coronary disease and a $3 \times 12 \mathrm{~mm}$ bare metal stent placed in the right coronary artery. She had a history of short bowel syndrome following emergency resection for ischaemic bowel just 2 years prior to receiving a long-term total parenteral nutrition (TPN). In view of clinical uncertainty surrounding effects of short bowel syndrome and TPN on clopidogrel responsiveness, ${ }^{1}$ platelet function testing was conducted.

Aspirin responsiveness was assessed by light transmission aggregometry (LTA; figure $1 \mathrm{~A}-\mathrm{C}$ ) and whole blood impedance aggregometry (WBA) using the multiplate (figure 2A,B). Results by both approaches confirmed adequate aspirin

AA
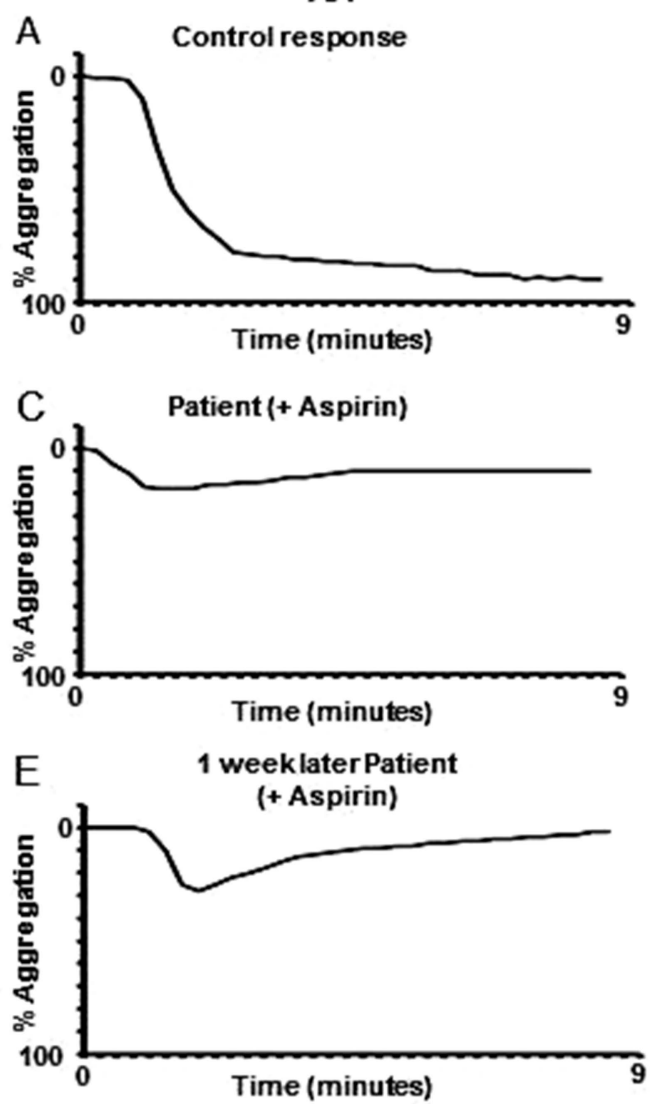

responsiveness. Clopidogrel responsiveness was only partial when assessed by LTA (figure 1) and absent when assessed by WBA (figure 2). When ticagrelor was used in place of clopidogrel, $90 \%$ inhibition of platelet aggregation was achieved by LTA. This was confirmed using the Verify Now P2Y12 test. Dual antiplatelet therapy with aspirin and clopidogrel showed a $4 \%$ inhibition of platelet aggregation compared with $69 \%$ with aspirin and ticagrelor. Medications were taken orally (not crushed).

Incidence of the rare but catastrophic complication of stent thrombosis ${ }^{2}$ is substantially reduced by potent platelet inhibition with dual antiplatelet therapy, most commonly with aspirin and clopidogrel. Inhibition of platelet aggregation by clopidogrel shows considerable variation between patients.
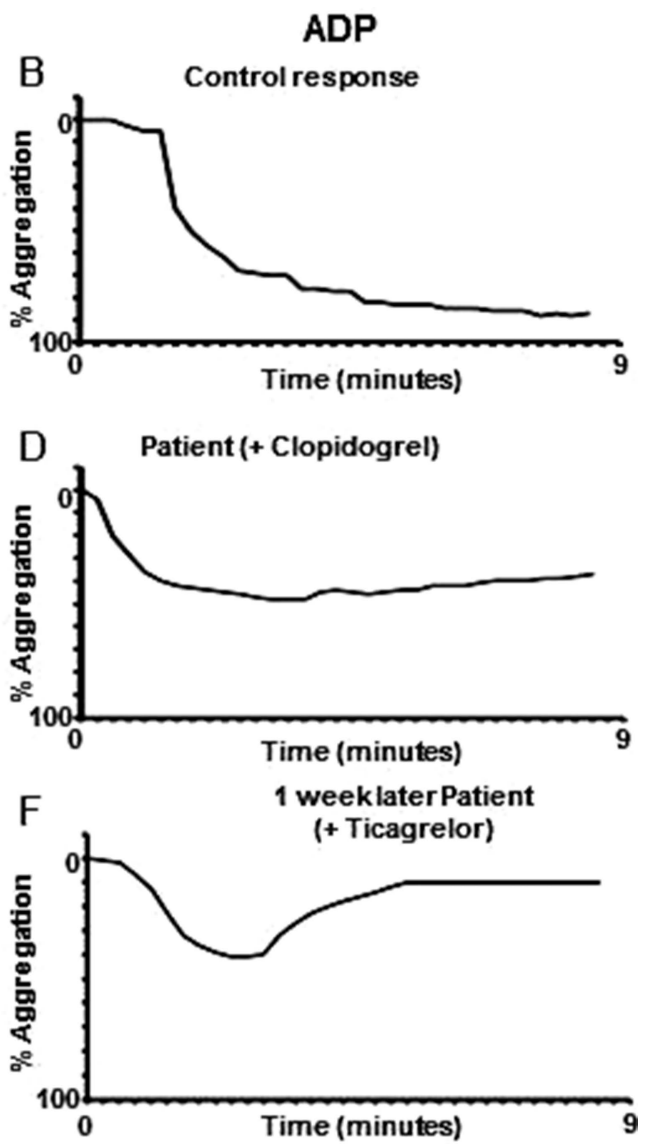

Figure 1 Light transmission aggregation. Measurements are in percentage light transmission. Arachidonic acid (AA) - response to $1 \mathrm{mM} \mathrm{AA}(\mathrm{A}, \mathrm{C}$ and $\mathrm{E})$. ADP-response to $20 \mu \mathrm{M} \mathrm{ADP}(\mathrm{B}, \mathrm{D}$ and $\mathrm{F})$. Control traces (A) aspirin and (B) clopidogrel. Patient's good response to aspirin $(C, 10 \%)$ and partial response to clopidogrel $(D, 50 \%)$. After switching to ticagrelor/aspirin and retesting 1 week later, good responses to aspirin $(E, 3 \%)$ and ticagrelor were observed $(F$, $10 \%)$. 

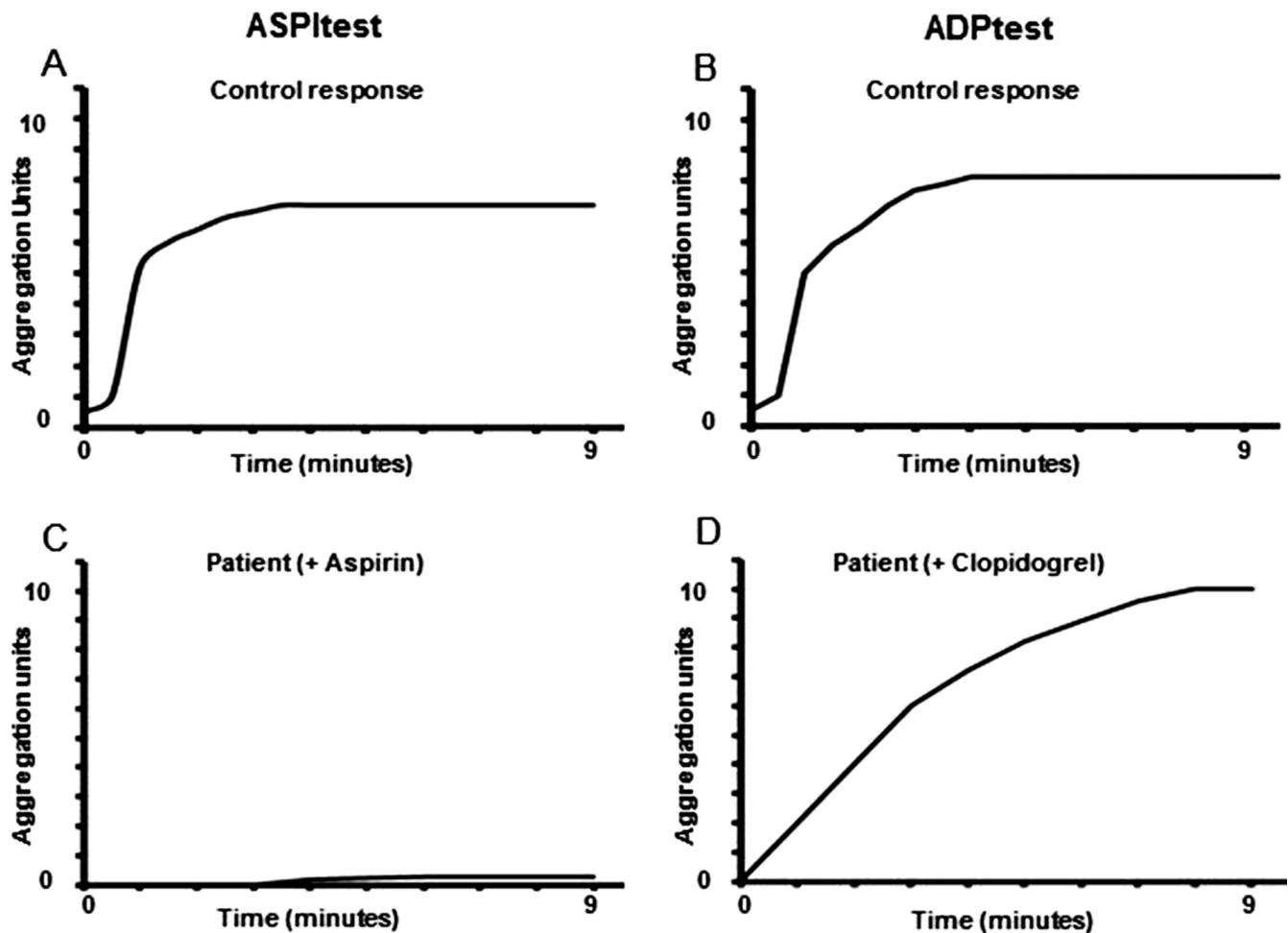

Figure 2 Whole blood impedance aggregometry (WBA). Measurements are in arbitrary aggregation units against time and reported as the area under the aggregation curve (AUC). ASPI test uses arachidonic acid. ADPI test uses ADP. Control traces (A) and (B) showing no platelet inhibition. Patient's good response to aspirin (C) in ASPI test and no response to clopidogrel in ADPI test (D).

Clopidogrel resistance may be genetic, ${ }^{3}$ for example, cytochrome P450 2C19 polymorphisms accounting for about $4.6 \%$ of the variability in responsiveness, or acquired, for example, in patients with diabetes or chronic renal failure.

\section{Learning points}

- Clopidogrel hyporesponders are recognised in the population and have an increased risk of adverse events including stent thrombosis following percutaneous coronary intervention.

- Newer antiplatelet agents do not rely on enzymatic conversion of a prodrug (such as ticagrelor) and are effective alternatives to clopidogrel in hyporesponsive patients.

- Malabsorbtion states requiring parenteral nutrition may contribute to reduced clopidogrel responsiveness. Platelet aggregometry or use of ticagrelor may be considered in this population.
Contributors GH and DA wrote the manuscript and prepared the figures. GH looked after the patient and had the idea of writing the case report. PH conducted the platelet function tests and provided interpretation and expertise from a haematological perspective. DA looked after the patient and helped with the literature search and knowledge for the cardiovascular aspect of the paper. RC was in charge of patient's care and oversaw the whole case report and provided cardiovascular expertise.

\section{Competing interests}

Patient consent Obtained.

Provenance and peer review Not commissioned; externally peer reviewed.

\section{REFERENCES}

1 Shaw AA, Hall SD, Franklin MR, et al. The influence of I-glutamine on the depression of hepatic cytochrome p450 activity in male rats caused by total parenteral nutrition. Drug Metab Dispos 2002;30:177-82.

2 van Werkum JW, Heestermans AA, de Korte Fl, et al. Long-term clinical outcome after a first angiographically confirmed coronary stent thrombosis: an analysis of 431 cases. Circulation 2009;119:828-34.

3 Simon T, Verstuyft C, Mary-Krause M, et al. Genetic determinants of response to clopidogrel and cardiovascular events. N Engl J Med 2009;360:363-75.

Copyright 2014 BMJ Publishing Group. All rights reserved. For permission to reuse any of this content visit

http://group.bmj.com/group/rights-licensing/permissions.

BMJ Case Report Fellows may re-use this article for personal use and teaching without any further permission.

Become a Fellow of BMJ Case Reports today and you can:

- Submit as many cases as you like

- Enjoy fast sympathetic peer review and rapid publication of accepted articles

- Access all the published articles

- Re-use any of the published material for personal use and teaching without further permission

For information on Institutional Fellowships contact consortiasales@bmjgroup.com

Visit casereports.bmj.com for more articles like this and to become a Fellow 